\title{
Management of Fused Tooth with Localized Gingival Growth - A Rare Entity
}

\author{
Pooja Yenubary, Harikumar Vemisetty, Jaya Nagendra Krishna, M. Anil Kumar \\ Department of Conservative Dentistry and Endodontics, Kamineni Institute of Dental Sciences, Narketpally, Telangana, India
}

Email for correspondences: yenubarypooja74@gmail.com

\begin{abstract}
Fusion is a developmental anomaly characterized by the union of two adjacent teeth. In the present article, a rare case of fusion involving two permanent maxillary lateral incisors is reported. The rarity, with which this entity appears, along with its complex characteristics, often makes it difficult to treat. The endodontic management of one such tooth is described here along with the successful treatment of a periradicular lesion.
\end{abstract}

Key words: Dental anomaly, endodontic treatment, fusion.

\section{INTRODUCTION}

In clinical practice, developmental anomalies of dentition are usually uncommon. Union of teeth is considered as developmental disturbance presenting commonly as fusion and gemination. ${ }^{[1,2]}$ Fusion could be defined as a conjunction of two separated tooth germs and identify as radiographically two separate pulp chambers and root canals. Depending on the stage of development at the time of union, the pulp chamber and root canal may be joined or separated. ${ }^{[3,4]}$ Fusion may occur between teeth of the same dentition or between supernumerary teeth. The prevalence of the defect is approximately $0.1-1 \%$ in the permanent dentition. ${ }^{[5-7]}$ Clinically, a broad crown with a vertical groove extending toward the gingival sulcus is seen. The pulp chamber and the root canals can be joined or separated. ${ }^{[7]}$ The etiology of tooth fusion is still unknown. Genetic predisposition, racial differences, the influence of pressure or physical forces that produce close contact between the developing tooth germs, and trauma have all been attributed as causative factors of tooth fusion. ${ }^{[8-10]}$

\section{Quick Response Code Article Info:}

\begin{tabular}{|l|l|}
\hline Quick Response Code & Article Info: \\
\hline doi: 10.5866/2018.10.10115 \\
$\begin{array}{l}\text { Received: 19-06-2018 } \\
\text { Revised: 22-07-2018 } \\
\text { Accepted: 21-08-2018 } \\
\text { Available Online: } 25-09-2018,(w w w . ~ \\
\text { nacd.in)@ NAD, 2018 - All rights } \\
\text { reserved }\end{array}$ \\
\hline
\end{tabular}

The present case report describes a rare case of a fused maxillary lateral incisor with gingival tissue growth which was successfully treated with non-surgical endodontic therapy.

\section{CASE REPORT}

A 21-year-old male patient reported to the Department of Conservative Dentistry and Endodontics, Kamineni Institute of Dental Sciences, Narketpally, Nalgonda, with a chief complaint of large tissue growth in the upper front tooth region for 1 year without any pain.

The clinical examination revealed that the right maxillary lateral incisor appeared to have an unusual clinical crown and presented as two separate and definite crowns joined along their length. The occurrence of fusion was only unilateral. A soft, erythematous, and pedunculated gingival growth was seen in between the clinical crowns of the right central and the fused tooth for 1 year, which started from a peanut size and gradually grew to the size of $3 \mathrm{~cm} \times 4 \mathrm{~cm}$ [Figure 1]. The patient gave a history of trauma when he was 4 years of age, and his deciduous dentition seems to be normal, but his permanent right lateral incisor erupted as a fused tooth. Patient reported to have asthma from his childhood and no familial history of dental anomalies.

Radiographic examination showed that the right lateral incisor with large crown divided into two halves along the length of its crown and root with two separate pulp chambers and definite 


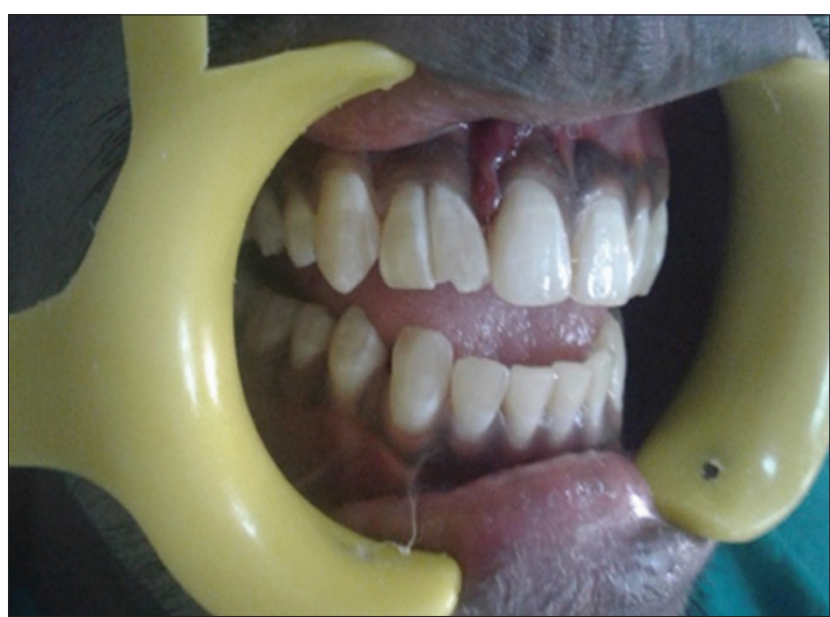

Figure 1: Pre-operative clinical picture showing tissue growth along with fused lateral tooth

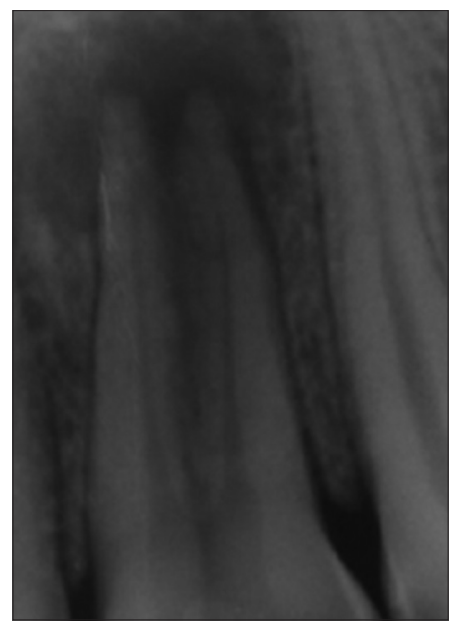

Figure 2: Pre-operative radiograph showing periapical radiolucency involving apices of both roots of the fused teeth

root canals. Periapical radiolucency is seen involving apices of both roots of the fused teeth [Figure 2]. Thermal and electrical pulp vitality tests elicited a negative response. Based on clinical and radiographic features, the present case was diagnosed as fusion of two normal crowns along their crown and root length with periapical abscess. Hence, non-surgical endodontic treatment for both crowns followed by esthetic correction of clinical crowns was planned.

Local anesthesia was administered. Rubber dam isolation could not be done in this case as the patient reported to have asthma. Two separate access openings were made to access the orifices of separate root canals. Continuous pus discharge was seen from both the canals. Complete drainage

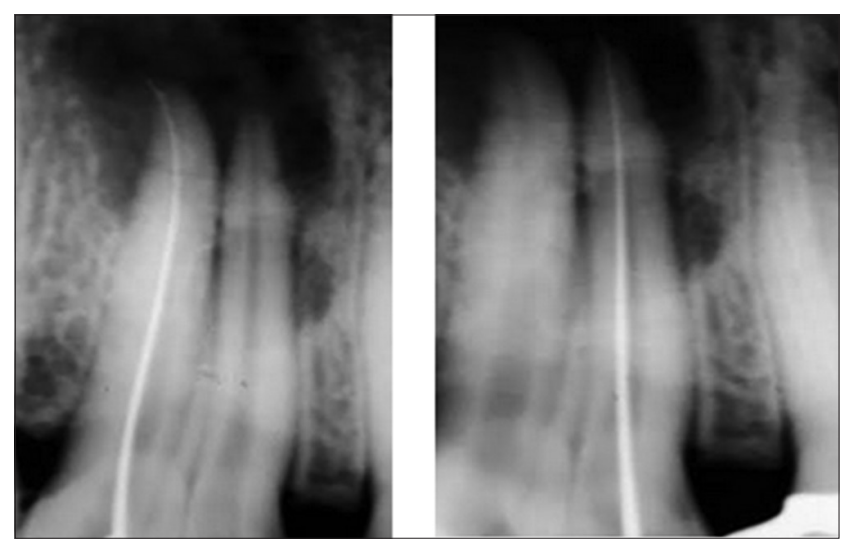

Figure 3: Working length determination which was $22 \mathrm{~mm}$ individually for both the teeth

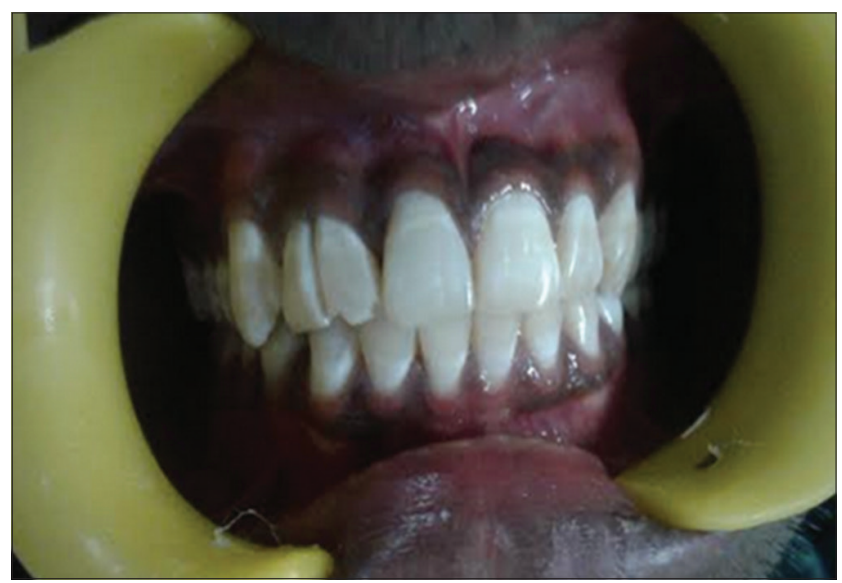

Figure 4: Clinical picture showing resolution of the lesion after 1 week with intracanal medicament

of the pus was done followed by working length determination which was $22 \mathrm{~mm}$ individually for both the teeth [Figure 3]. Cleaning and shaping was achieved using stainless steel K-files (Mani, Japan) by step-back technique. Final apical file used was 45 size (ISO 0.02 taper) for both the canals. Irrigation was done with alternate solutions of sodium hypochlorite, saline, and final rinse of chlorhexidine (CHX). The canals were finally flushed with normal saline and then dried with absorbent paper points. A mixture of calcium hydroxide powder and chlorhexidine was used as an intracanal medicament, and the patient was recalled after 1 week. In the next visit on clinical examination, there was complete resolution of the gingival overgrowth [Figure 4]. A thorough irrigation was done with saline, chlorhexidine and intracanal calcium hydroxide dressing were given. After 1 week, the patient was recalled and 


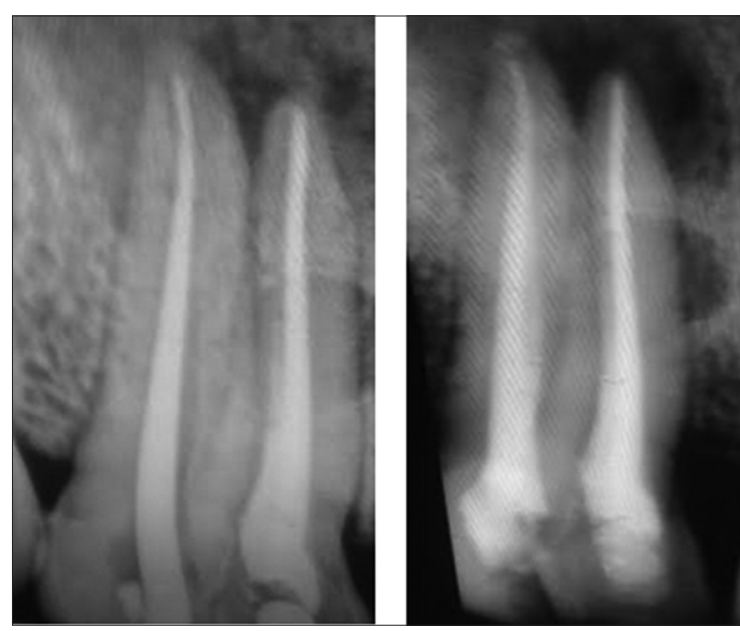

Figure 5: IOPA radiograph showing complete obturation along with post-endodontic restoration done with GIC

he was asymptomatic with dry canals with a slight decrease in the periapical radiolucency, and hence, obturation was planned. Obturation was done using zinc oxide sealer with gutta-percha by lateral compaction technique. The coronal access was sealed with glass ionomer cement (GC Fuji II, GC Corp, Tokyo, Japan) [Figure 5]. The patient was recalled for esthetic correction of the large crown; however, he refused as he was accustomed to his original crown.

\section{DISCUSSION}

Knowledge of the morphological and anatomical characteristics of the root canal system is the key to ensure a successful treatment. ${ }^{[11,12]}$ The morphology of fusion has to be differentiated from similar developmental anomalies of the tooth for successful endodontic and esthetic management. A suggested scheme of classification is as follows:

Gemination (cleavage of a single tooth germ) - partial cleavage (true gemination); complete cleavage (twinning). Fusion (two separate tooth germs fused during formative stage) - union by enamel and dentin (true fusion); union by dentin and/or cementum (late fusion); a late fusion by cementum is called a concrescence. ${ }^{[13,14]}$ In the present case, two definite and separate root canals were present. Both the clinical and radiographic findings were suggestive of fusion. The reason of the fusion, in this case, might be a history of trauma, as the patient has reported during his childhood. In the present case, a soft pedunculated gingival growth was seen extending from the marginal gingiva between the central incisor and the fused tooth to the labial sulcus which is of $3 \mathrm{~cm} \times 4 \mathrm{~cm}$ in size. The possible reason for the occurrence of such gingival growth could be due to chronic root canal infection, in which an asymptomatic papule of granulation tissue often forms on the gingiva in response to the chronic irritation of the drainage. This papule is the opening of a sinus tract or fistula. The sinus tract will close when the source of the infection is eliminated, but the papule may persist in the form of a fibroma. [15] In the present case, a thorough irrigation with sodium hypochlorite, application of calcium hydroxide along with chlorhexidine as intracanal medicament resulted in complete disappearance of the gingival growth in 1 week. Various studies have proved that chlorhexidine and sodium hypochlorite were the best among the irrigants, as they could reduce the bacterial counts rapidly ${ }^{[16,17]}$ Both these irrigants eliminate the Gram-positive and the Gram-negative anaerobic bacteria in $15 \mathrm{~min}$. [18] The presence of calcium hydroxide in the paste formulations acts as a physical barrier which will stay in the root canal for longer thus preventing root canal reinfection, interrupting the nutrient supply to the remaining bacteria and thus delaying recontamination. Moreover, the presence of $\mathrm{CHX}$ adds substantivity to the formulations due to its absorption capacity and slow liberation of active molecules by dental tissues. ${ }^{[19,20]}$ In the present case, complete resolution of the gingival growth was seen in a week of intracanal dressing of calcium hydroxide and chlorhexidine.

\section{CONCLUSION}

The anatomy of the root canal system of fused teeth requires special attention in the diagnosis and treatment planning, making careful clinical and radiographic examinations essential for the successful endodontic and restorative treatment of such cases.

\section{REFERENCES}

1. Knezevi A, Travan S, Tarle Z, Sutalo J, Jankovi B, Ciglar I, et al. Double tooth. Coll Antropol 2002;26:667-72.

2. Cho KM, Jang JH, Park SH. Clinical management of a fused upper premolar with supernumerary tooth: A case report. Restor Dent Endod 2014;39:319-23.

3. Aydemir S, Ozel E, Arukaslan G, Tekce N. Clinical management of a fused mandibular lateral incisor with supernumerary tooth: A case report. Dent Res J (Isfahan) 2016;13:80-4

4. Nunes E, de Moraes IG, de Novaes PM, de Sousa SM. Bilateral fusion of mandibular second molars with supernumerary teeth: Case report. Braz Dent J 2002;13:137-41. 
5. Shafer WG. Textbook of Pathology. $1^{\text {st }}$ ed. Philadelphia, PA: WB Saunders Company; 1983. p. 38-9.

6. Cardoso MA, Noites RB, Martins MA, Paulo MP. Nonsurgical endodontic retreatment of fused teeth with transposition: A case report. Restor Dent Endod 2016;41:148-53.

7. Aryanpour S, Bercy P, Van Nieuwenhuysen JP. Endodontic and periodontal treatments of a geminated mandibular first premolar. Int Endod J 2002;35:209-14.

8. Zeylabi A, Shirani F, Heidari F, Farhad AR. Endodontic management of a fused mandibular third molar and distomolar: A case report. Aust Endod J 2010;36:29-31.

9. Kaffe I, Littner MM, Begleiter A, Buchner A. Fusion of permanent molars. Quintessence Int Dent Dig 1982;13:1237-9.

10. Sosa JF, Pereira JN. Endodontic treatment of a rare case of fusion between a right mandibular third molar and a distomolar. ENDO (Lond Engl) 2014;8:223-7.

11. Mancuso A. The treatment of fusion and supernumerary maxillary central incisors: A case report. Gen Dent 2003;51:343-5.

12. Baratto-Filho F, Leonardi DP, Crozeta BM, Baratto SP, Campos EA, Tomazinho FS, et al. The challenges of treating a fused tooth. Braz Dent J 2012;2:256-62.

13. Tannenbaum KA, Alling EE. Anomalous tooth development. Case reports of gemination and twinning. Oral Surg Oral
Med Oral Pathol 1963;16:883-7.

14. Jain AA, Yeluri R, Munshi AK. Gemination or fusion? A diagnostic dilemma. Dentistry 2014;4:196.

15. Stefanac S, Nesbit S. Diagnosis and Treatment Planning in Dentistry. $3^{\text {rd }}$ ed. St. Louis: Mosby; 2017.

16. Siqueira JF Jr., Batista MM, Fraga RC, de Uzeda M. Antibacterial effects of endodontic irrigants on blackpigmented gram-negative anaerobes and facultative bacteria. J Endod 1998;24:414-6.

17. Jeansonne MJ, White RR. A comparison of $2.0 \%$ chlorhexidine gluconate and $5.25 \%$ sodium hypochlorite as antimicrobial endodontic irrigants. J Endod 1994;20:276-8.

18. Spratt DA, Pratten J, Wilson M, Gulabivala K. An in vitro evaluation of the antimicrobial efficacy of irrigants on biofilms of root canal isolates. Int Endod J 2001;34:300-7.

19. Bilgi PS, Shah NC, Mehta J. Comparative evaluation of mixture of calcium hydroxide and chlorehexidine with triple antibiotic paste and combination of calcium hydroxide, chlorhexidine and lycopene on incidence of interappointment flare-up: An in vivo study. Int J Clin Dent Res 2017;1:10-4.

20. Gomes BP, Vianna ME, Sena NT, Zaia AA, Ferraz CC, de Souza Filho FJ, et al. In vitro evaluation of the antimicrobial activity of calcium hydroxide combined with chlorhexidine gel used as intracanal medicament. Oral Surg Oral Med Oral Pathol Oral Radiol Endod 2006;102:544-50. 